\title{
Ultrasonographic evaluation of ovarian morphology and blood flow in prepubertal and pubertal cats
}

\author{
Rosario Vercellini $^{1,2,3}$ | Cristina Gobello, ${ }^{1,3}$ | Florencia D'Francisco ${ }^{1,3}$ | \\ Silvia Olguín $^{2}$ | Analía Arizmendi ${ }^{3,4}$ | Raúl Rodríguez ${ }^{1,2}$ | Daniel Osvaldo Arias ${ }^{1,4}$ | \\ Paula G. Blanco ${ }^{1,3,4}$
}

${ }^{1}$ Laboratory of Reproductive

Physiology, Faculty of Veterinary

Sciences, National University of La Plata

(FVS-NULP), La Plata, Argentina

${ }^{2}$ Radiology Service, FVS-NULP, La Plata, Argentina

${ }^{3}$ CONICET, La Plata, Argentina

${ }^{4}$ Cardiology Service, FVS-NULP, La Plata, Argentina

\section{Correspondence}

Rosario Vercellini, Laboratory of Reproductive Physiology, Faculty of Veterinary Sciences, National University of La Plata (FVS-NULP), La Plata, Argentina.

Email: rvercellini@fcv.unlp.edu.ar

\begin{abstract}
The aim of this study was to evaluate two-dimensional and Doppler ultrasonographic changes of feline ovaries before and during puberty. Nine, 3-month-old female cats were followed until puberty (Day 1). Two-dimensional and Doppler ultrasound evaluations of the ovaries were carried out on Days $-50,-20,-7$ and 1 . Longitudinal and transverse sections of the ovaries were measured and all anechoic spherical structures were considered to be follicles. The number of follicles $>1 \mathrm{~mm}$ and the maximum diameter of the largest follicle were recorded. Peak systolic velocity and end diastolic velocity of intraovarian arteries were also measured to automatically calculate the resistive index (RI). The mean ovarian longitudinal diameter increased gradually throughout the study from 8.6 to $10.7 \mathrm{~mm}(p<0.05)$. While four cats presented multiple anechoic spherical structures $<1 \mathrm{~mm}$ diameter throughout the study, the remaining five animals had these structures only on Days -50 and -20 . On Days -20 , -7 and 1 , the mean number of follicles were $1.4 \pm 0.7,2.5 \pm 0.8$ and $4.8 \pm 1$ respectively $(p<0.01)$. The largest follicles at the same time points were $1.1 \pm 0.2 \mathrm{~mm}$, $1.9 \pm 0.3 \mathrm{~mm}$ and $2.6 \pm 0.5 \mathrm{~mm}$ respectively $(p<0.05)$. The $\mathrm{RI}$ of the intraovarian arteries declined throughout the study period $(p<0.01)$. It is concluded that, in female cats, ovarian dimensions, follicle number and intraovarian blood flow increased from 3 months of age to puberty.

KEYWORDS

cat, Doppler, follicle, ovary, puberty, ultrasound
\end{abstract}

\section{1 | INTRODUCTION}

Puberty is a gradual, quantitative process by which an animal matures into an adult capable of sexual reproduction (Gobello, 2014). The onset of puberty in female cats occurs at 4-12 months of age, depending on breed, photoperiod and body weight (BristolGould \& Woodruff, 2006). Few prepubertal changes have been identified in this species (Wildt, Chan, Seager, \& Chakraborty, 1981) and, therefore, owners' awareness of puberty is usually retrospective. 
Increased understanding of feline reproduction might be beneficial to improve biotechnologies, for breeding of both domestic and wild endangered species as well as for biomedical research.

In female cats, the follicular dynamics of the anovulatory and mechanically induced ovulatory cycles have been described using transabdominal ultrasonography (Malandain et al., 2011). However, the ultrasonographic characterization of domestic cat ovaries during sexual maturation has not yet been reported.

Ovarian morphology can be evaluated using two-dimensional ultrasound, but this technique cannot provide information about organ function, such as vascular perfusion (Herzog \& Bollwein, 2007). In dogs and dairy cattle, ovarian Doppler ultrasound has been successfully used to assess follicular and luteal phases (Köster, Poulsen Nautrup, \& Gunzel-Apel, 2001; Matsui \& Miyamoto, 2009; Bergeron, Nykamp, Brisson, Madan, \& Gartley, 2013). Doppler examination of the feline ovary has not been reported yet.

Thus, the aim of this study was to evaluate two-dimensional and Doppler ultrasonographic ovarian changes before and during feline puberty.

\section{2 | MATERIALS AND METHODS}

\section{1 | Animals}

Nine, domestic short-hair, 3 months old, $1.1 \pm 0.09 \mathrm{~kg}$ female kittens were included in the study. The cats were born in our Institutional cat colony from different litters and reared free in indoor enriched catteries ( 2 rooms $4 \times 3 \mathrm{~m}$ with a 14L:10D photoperiod), weaned at 40 days of age and fed with dry commercial premium kitten food and water ad libitum. This study was reviewed and approved by the Animal Care and Use Committee of the Veterinary School of the National University of La Plata, Argentina, and all experiments were conducted under the guidelines established in The Guide for The Care and Use of Laboratory Animals, USA (IACUC N 56-2-16T).

\subsection{Follow up}

The queens were observed daily for reproductive behaviour and vaginal cytology was evaluated three times a week, or whenever oestrus signs appeared. The onset of puberty (Day 1) was diagnosed by the first appearance of more than $80 \%$ keratinized vaginal epithelial cells and a clean background in vaginal smears for at least three successive samples obtained every other day (Mills, Valli, \& Lumsden, 1979). The expression of typical sexual behaviours (i.e., rubbing on objects, rolling, lordosis, tail lateralization and vocalizing) was also included as a requirement (Johnston, Root-Kustritz, \& Olson, 2001). All cats were weighed once a week using a calibrated electronic scale (SF-400, China).

\section{3 | Ovarian ultrasonography}

Two-dimensional ultrasonography, colour-coded and pulsed-wave Doppler evaluation of the ovaries were carried out on Days $-50,-20$
-7 and 1, with a $14 \mathrm{MHz}$ linear-array transducer (Toshiba Nemio XG, Japan). Experimental days were retrospectively determined. The cats were placed in dorsal recumbency without sedation or anaesthesia. Acoustic gel was applied to the transducer and coupled directly to the clipped skin. The ovaries were identified near the caudal pole of the ipsilateral kidney. Their location was facilitated by the appearance of the edge artefact dorsal to each ovary (Davidson \& Baker, 2009; Gatel, Gory, Chalvet-Monfray, Saunders, \& Rault, 2016). Longitudinal and transverse diameters of the ovaries were measured and all anechoic spherical structures were considered to be antral follicles (Malandain et al., 2011; Figure 1). In each ovary, the number of follicles $>1 \mathrm{~mm}$ was recorded. The maximum diameter (MD; $\mathrm{mm}$ ) of the largest follicle was additionally determined.

Intraovarian vascularization was examined using colour flow Doppler ultrasonography. The size of the colour-coded area was generally limited to the maximum extent of the ovary, and the filter and gain were adjusted for each scan in order to obtain optimal images (Figure 2). Pulsed-Doppler sample gate was placed over the artery and minor positional adjustments were made to obtain the waveforms (Köster et al., 2001). To minimize variability, three uniform consecutive waveforms were recorded by the same trained operator.

Peak systolic velocity and end diastolic velocity of intraovarian arteries were measured to automatically calculate the resistive index (RI; Blanco, Arias, \& Gobello, 2008; Figure 2).

\subsection{Statistical analysis}

Normal distribution of the data was determined by the Shapiro-Wilk test. All two-dimensional and Doppler parameters of the left and right ovaries were averaged.

Repeated measures ANOVA followed by a Tukey test were carried out to evaluate the effect of time on the two-dimensional and Doppler ultrasonographic parameters (SPSS 18.0; SPSS, Chicago, IL, USA). The level of significance was set at $p<0.05$.

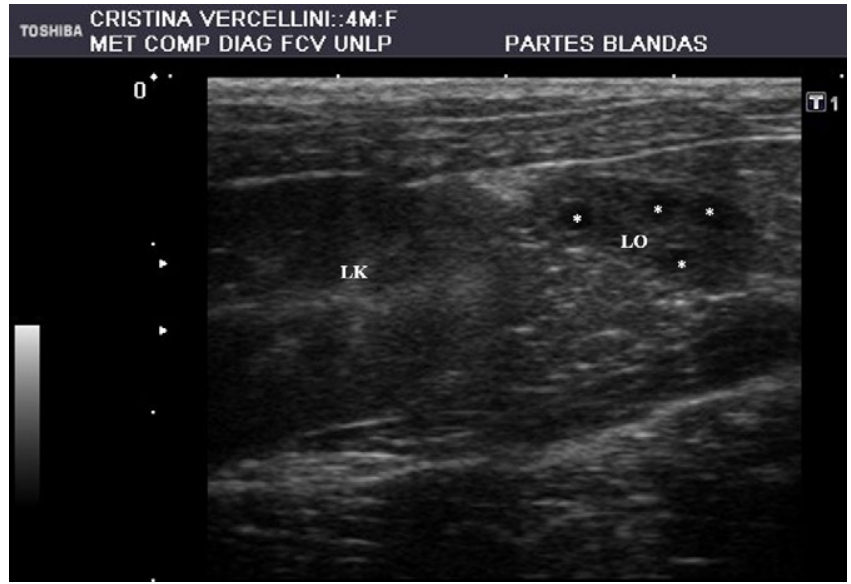

FIGURE 1 Longitudinal image of the left ovary of a 19-week-old prepubertal female cat. Four structures $>1 \mathrm{~mm}$ were considered as follicles (asterisks). LO: Left ovary; LK: Left kidney 


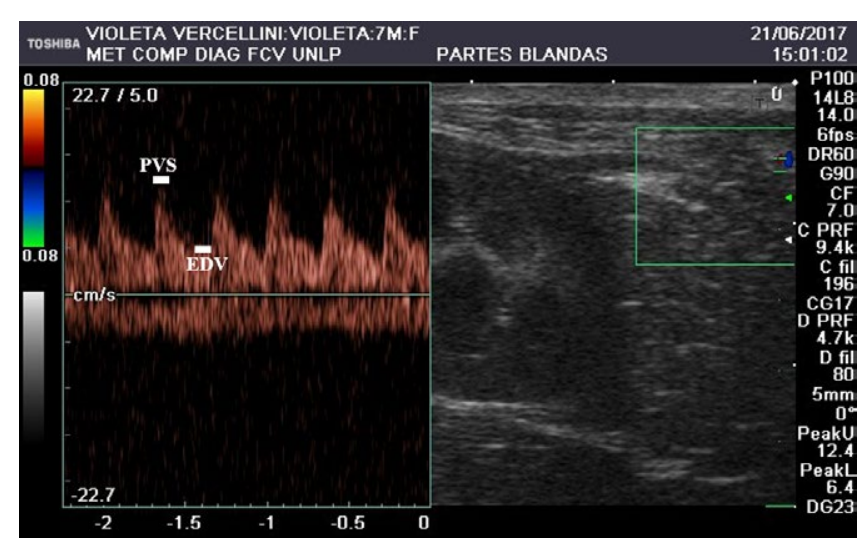

FIGURE 2 Pulsed-wave Doppler ultrasound recording of intraovarian arteries of a 31-week-old prepubertal female cat. EDV: end diastolic velocity; PSV: peak systolic velocity

\section{3 | RESULTS}

The female cats achieved puberty at $31 \pm 3.1$ weeks of age weighing $2.4 \pm 0.1 \mathrm{~kg}$, which represented $88 \pm 4 \%$ of their adult body weight.

In all of the two-dimensional sonographic images the ovaries appeared ovoid and hypoechoic compared to the surrounding tissues. The mean ovarian longitudinal diameter increased gradually throughout the study from 8.6 to $10.7 \mathrm{~mm}$ ( $p<0.05$; Figure 3 ), while the transverse diameter slightly increased from 4.2 to $4.5 \mathrm{~mm}$ ( $p>0.05$; Figure 3 ). While four cats presented multiple anechoic spherical structures $<1 \mathrm{~mm}$ diameter throughout the study, the remaining five animals had these structures only on Days -50 and -20. The smallest of these structures were $0.7 \mathrm{~mm}$.

On Days $-20,-7$ and 1, the mean number of follicles were $1.4 \pm 0.7$, $2.5 \pm 0.8$ and $4.8 \pm 1 \mathrm{~mm}$, respectively $(p<0.01$; Figure 4). The largest follicles at the same time points were $1.1 \pm 0.2 \mathrm{~mm}, 1.9 \pm 0.3 \mathrm{~mm}$ and $2.6 \pm 0.5 \mathrm{~mm}$ respectively ( $p<0.05$; Figure 4).

Ovarian blood flow waveforms in the present study presented a systolic peak followed by a diastolic wave continuous with systole and extending throughout the remainder of the cardiac cycle to the next systole. The morphology of the waveforms did not change in the course of the experiment. The RI of the intraovarian arteries declined throughout the study period ( $p<0.01$; Figure 5).

\section{DISCUSSION}

To the best of our knowledge, the results of this article provide the first ultrasonographic report of the structural and blood flow changes of the feline ovary before and during puberty. During prepubertal development, ovarian size progressively increased up to $31 \pm 3.1$ weeks of age. This is similar to a previous report in which the ovarian weight of 3-month-old prepubertal cats was significantly lower than that of adult cats (Mehl, Khalid, Srisuwatanasagul, Swangchan-Uthai, \& Sirivaidyapong, 2017). Another report in prepubertal cats stated that ovarian weight increased rapidly until 3-4 months old when the study was concluded (Uchikura, Nagano,
\& Hishinuma, 2010). The present ultrasonographic findings complement and extend the follow-up period of feline ovarian growth.

In these female cats, the increase in ovarian size was accompanied by an increase in the number and size of antral follicles. This is in agreement with changes in prepubertal cows and gilts, where a positive relationship between the number of antral follicles and the size of the ovaries was found (Honaramooz et al., 2004; Lents, Cushman, \& Freking, 2014). Coincident with this, histological studies in prepubertal cats stated that the increase in ovarian weight was accompanied by the increase in the number and size of antral follicles (Uchikura et al., 2010; Mehl et al., 2017).

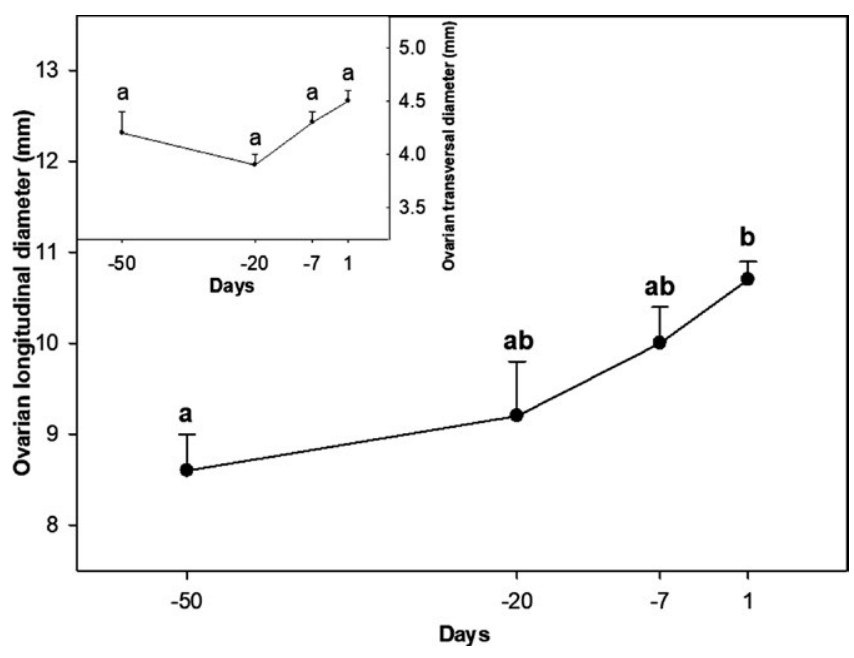

FIGURE 3 Ovarian longitudinal diameter (mean \pm SEM) of nine female cats evaluated from Day -50 up to puberty (Day 1 was defined as the onset of pubertal estrus). Different letters indicate differences $(p<0.05)$ among days. Inset: Ovarian transverse diameter (mean \pm SEM) of the same animals

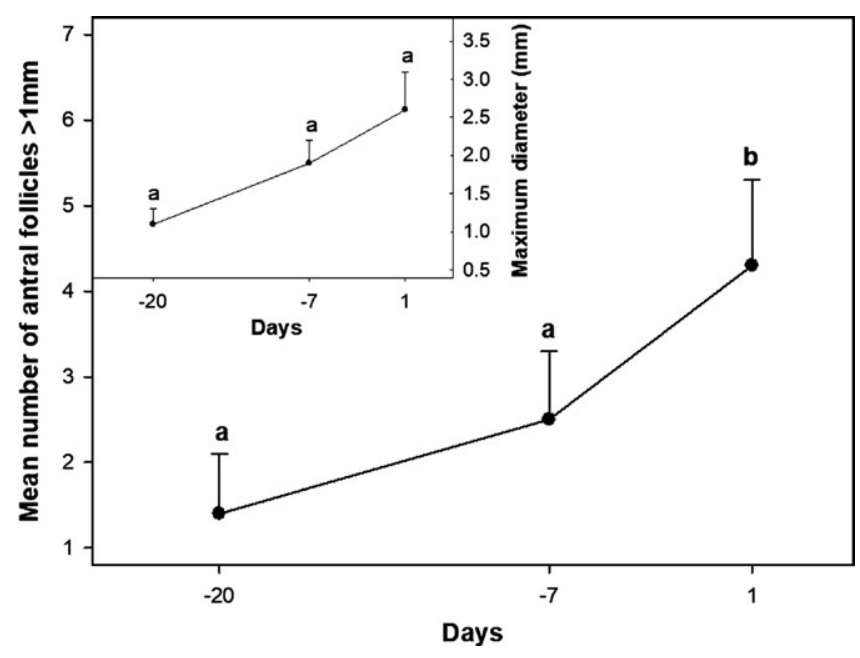

FIGURE 4 Mean number of follicles $>1 \mathrm{~mm}$ (mean \pm SEM) of the same cats of Figure 3 evaluated from Day -20 up to puberty (Day 1 was defined as the onset of pubertal estrus). Different letters indicate differences $(p<0.05)$ among days. Inset: Maximum diameter (mean \pm SEM) of the largest follicle in the same animals 


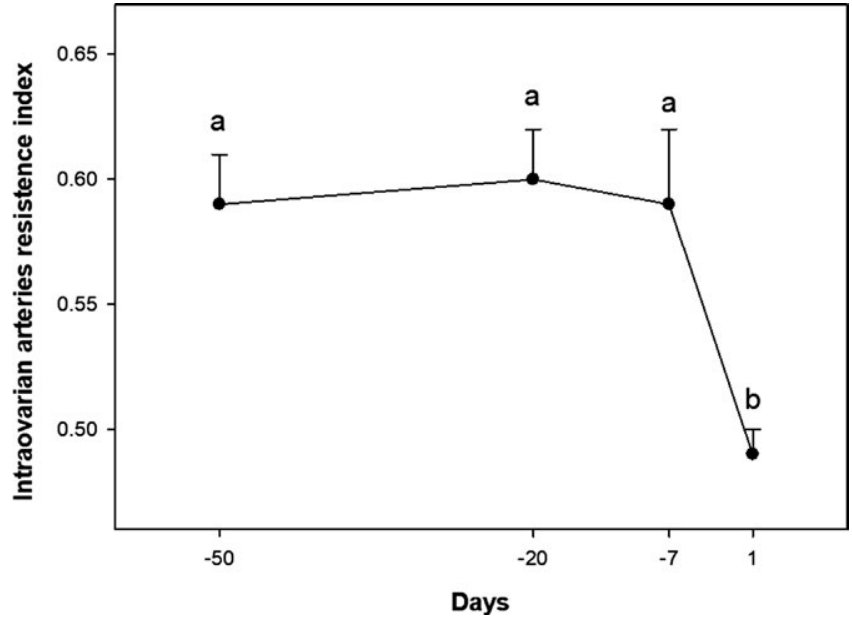

FIGURE 5 Resistive index of intraovarian arteries (mean \pm SEM) of the same cats of Figure 3 evaluated from Day -50 up to puberty (Day 1 was defined as the onset of pubertal estrus). Different letters indicate differences $(p<0.05)$ among days

In adult mammals, it has been postulated that numerous follicles are present in the ovaries at all times and the follicles destined to ovulate begin to enlarge about mid-cycle, showing a sudden enlargement just after the onset of heat (Evans, 2003). In postpubertal bitches, a shift from small to large $(>4 \mathrm{~mm}$ ) follicles has been described to occur 2 days prior to the luteinizing hormone surge (England, Russo, \& Freeman, 2009).

In this feline study, multiple anechoic structures $<1 \mathrm{~mm}$ diameter were ultrasonographically detected from Day -50 onwards. In four of nine cats (44\%), these structures and follicles $>1 \mathrm{~mm}$ where simultaneously observed from $24 \pm 4$ weeks of age onwards. This finding may indicate that in the female cat, the ultrasonographic detection of growing follicles is possible far before the onset of the first oestrus.

In this study, the increase in ovarian size and follicular number was associated with a decline in the RI of intraovarian arteries. This finding may indicate that ovarian blood flow increases during sexual development in female cats. In cows, physiological angiogenesis plays an essential role in the female reproductive system, occurring cyclically in the ovary and uterus (Matsui \& Miyamoto, 2009). In cattle, hemodynamic changes are involved in the cyclic remodelling of ovarian tissue that occurs during follicular growth and ovulation. The present study demonstrated that ovarian Doppler ultrasound is a useful and reliable technique for evaluating ovarian vascular function in female cats, thus identifying ovarian activity before the onset of puberty. The identification of early prepubertal events in this species might be applied for contraceptive and biotechnological purposes.

Further ultrasonographic studies on sexual development and ovarian function in queens are required to allow a better understanding of normal feline reproductive physiology.

It is concluded that, in female cats, ovarian dimensions, follicle number and intraovarian blood flow increased from 3 months of age to puberty.

\section{ACKNOWLEDGEMENTS}

This study was partially funded by the University Incentive Program of Teaching and Research 11/V233. The authors are career scientists (P.G. Blanco and C. Gobello) and research fellows (R. Vercellini, F. D' Francisco and A. Arizmendi) of the National Research Council (CONICET) of Argentina.

\section{CONFLICT OF INTEREST}

None of the authors of this article has a financial or personal relationship with other people or organizations that could inappropriately influence or bias the content of the paper.

\section{AUTHOR CONTRIBUTIONS}

Dr Vercellini performed the ultrasound and clinical examinations of the cats, acquired and analysed the data and drafted the paper. Dr Gobello participated in the experimental design, data interpretation and the paper drafting. Dr D'Francisco contributed to the ultrasound and clinical examinations of the cats and data acquisition. Dr Olguín participated in the ultrasound and clinical examinations of the cats and data acquisition. Dr Arizmendi contributed to the ultrasound examinations of the cats and data analysis. Dr Rodríguez contributed to the ultrasound examinations of the cats, data interpretation and paper drafting. Dr Arias contributed to the clinical and ultrasound examinations of the cats, data interpretation and paper drafting. Dr Blanco designed the study, participated in the ultrasound examinations, analysed the data and drafted the paper.

\section{REFERENCES}

Badouraki, M., Christoforidis, A., Economou, I., Dimitriadis, A. S., \& Katzos, G. (2008). Sonographic assessment of uterine and ovarian development in normal girls aged 1 to 12 years. Journal of Clinical Ultrasound, 36, 539-544. https://doi.org/10.1002/jcu.20522

Battaglia, C., Mancini, F., Regnani, G., Persico, N., lughetti, L., \& De Aloysio, D. (2003). Pelvic ultrasound and color Doppler findings in different isosexual precocities. Ultrasound Obstetrics Gynecology, 22, 277-283. https://doi.org/10.1002/uog.154

Bergeron, L. H., Nykamp, S. G., Brisson, B. A., Madan, P., \& Gartley, G. J. (2013). An evaluation of B-mode and color Doppler ultrasonography for detecting periovulatory events in the bitch. Theriogenology, 79, 274-283. https://doi.org/10.1016/j.theriogenology.2012.08.016

Blanco, P. G., Arias, D. O., \& Gobello, C. (2008). Doppler ultrasound in canine pregnancy. Journal of Ultrasound in Medicine, 27, 1745-1750. https://doi.org/10.7863/jum.2008.27.12.1745

Bristol-Gould, S., \& Woodruff, T. K. (2006). Folliculogenesis in the domestic cat (Felis catus). Theriogenology, 66, 5-13. https://doi. org/10.1016/j.theriogenology.2006.03.019

Coelho Neto, M. A., Ludwin, A., Borrell, A., Benacerraf, B., Dewailly, D., da Silva Costa, F., ... Martins, W. P. (2018). Counting ovarian antral follicles by ultrasound: A practical guide. Ultrasound in Obstetrics \& Gynecology, 51, 10-20. https://doi.org/10.1002/uog.18945

Davidson, A. P., \& Baker, T. W. (2009). Reproductive ultrasound of the bitch and queen. Topics in Companion Animal Medicine, 24, 55-63. https://doi.org/10.1053/j.tcam.2008.11.002 
England, G.C., Russo,M.,\& Freeman,S.L.(2009). Folliculardynamics, ovulation and conception rates in bitches. Reproduction in Domestic Animals, 44, 53-58. https://doi.org/10.1111/j.1439-0531.2009.01416.x

Evans, A. C. O. (2003). Characteristics of ovarian follicle development in domestic animals. Reproduction in Domestic Animals, 38, 240-246. https://doi.org/10.1046/j.1439-0531.2003.00439.x

Gatel, L., Gory, G., Chalvet-Monfray, K., Saunders, J. H., \& Rault, D. N. (2016). Intra- and inter-observer variability in ultrasonographical measurements of the uterus and ovaries in healthy, non-pregnant queens. Journal of Feline Medicine and Surgery, 18(2), 110-117. https://doi.org/10.1177/1098612X15574317

Gobello, C. (2014). Prepubertal and pubertal canine reproductive studies: Conflicting aspects. Reproduction in Domestic Animals, 49, e70e73. https://doi.org/10.1111/rda.12414

Herzog, K., \& Bollwein, H. (2007). Application of Doppler Ultrasonography in cattle reproduction. Reproduction in Domestic Animals, 42, 51-58. https://doi.org/10.1111/j.1439-0531.2007.00903.x

Honaramooz, A., Aravindakshan, J., Chandolia, R. K., Beard, A. P., Bartlewski, P. M., Pierson, R. A., \& Rawlings, N. C. (2004). Ultrasonographic evaluation of the pre-pubertal development of the reproductive tract in beef heifers. Animal Reproduction Science, 80 , 15-29. https://doi.org/10.1016/S0378-4320(03)00136-2

Ivarsson, S. A., Nilsson, K. O., \& Persson, P. H. (1983). Ultrasonography of the pelvic organs in prepubertal and postpubertal girls. Archives of Disease in Childhood, 58, 352-354. https://doi.org/10.1136/adc.58.5.352

Johnston, S. D., Root-Kustritz, M. V., \& Olson, P. N. S. (2001). The feline estrous cycle. In Johnston, S. D., Root-Kustritz, M. V., \& Olson, P. N. S. (Eds.) Canine and feline theriogenology (pp. 396-405). Philadelphia, PA: WB Saunders.

Kauffold, J., Rautenberg, T., Richter, A., Waehner, M., \& Sobiraj, A. (2004). Ultrasonographic characterization of the ovaries and the uterus in prepubertal and pubertal gilts. Theriogenology, 61, 16351648. https://doi.org/10.1016/j.theriogenology.2003.09.012

Köster, K., Poulsen Nautrup, C., \& Günzel-Apel, A. R. (2001). A Doppler ultrasonographic study of cyclic changes of ovarian perfusion in the Beagle bitch. Reproduction, 122, 453-461. https://doi.org/10.1530/ rep.0.1220453

Lents, C. A., Cushman, R. A., \& Freking, B. A. (2014). Measures of the ovaries and uterus during development of gilts selected for differences in uterine capacity. Journal of Animal Science, 92, 2433-2439. https:// doi.org/10.2527/jas.2013-7205

Malandain, E., Rault, D., Froment, E., Baudon, S., Desquilbet, L., Begon, D., \& Chastant-Maillard, S. (2011). Follicular growth monitoring in the female cat during estrus. Theriogenology, 76, 1337-1346. https://doi. org/10.1016/j.theriogenology.2011.06.002
Marshall, W. A., \& Tanner, J. M. (1969). Variations in the pattern of pubertal changes in girls. Archives of Disease in Childhood, 44, 291-303. https://doi.org/10.1136/adc.44.235.291

Marshall, W. A., \& Tanner, J. M. (1970). Variations in the pattern of pubertal changes in boys. Archives of Disease in Childhood, 45, 13-23. https://doi.org/10.1136/adc.45.239.13

Martinat-Botté, F., Royer, E., Venturi, E., Boisseau, C., Guillouet, P., Furstoss, V., \& Terqui, M. (2003). Determination by echography of uterine changes around puberty in gilts and evaluation of a diagnosis of puberty. Reproduction Nutrition Development, 43, 225-236. https://doi.org/10.1051/rnd:2003022

Matsui, M., \& Miyamoto, A. (2009). Evaluation of ovarian blood flow by colour Doppler ultrasound: Practical use for reproductive management in the cow. Veterinary Journal, 181, 232-240. https://doi. org/10.1016/j.tvjl.2008.02.027

Mehl, N. S., Khalid, M., Srisuwatanasagul, S., Swangchan-Uthai, T., \& Sirivaidyapong, S. (2017). Comparison of the ovarian and uterine reproductive parameters, and the ovarian mRNA and protein expression of LHR and FSHR between the prepubertal and adult female cats. Reproduction in Domestic Animals, 52, 41-44. https://doi. org/10.1111/rda.12926

Mills, J. N., Valli, V. E., \& Lumsden, J. H. (1979). Cyclical changes of vaginal cytology in the cat. The Canadian Veterinary Journal, 20, 95-101.

Perry, G. A., \& Cushman, R. A. (2016). Invited review: Use of ultrasonography to make reproductive management decisions. The Professional Animal Scientist, 32, 154-161. https://doi.org/10.15232/ pas.2015-01446

Uchikura, K., Nagano, M., \& Hishinuma, M. (2010). Evaluation of follicular development and oocyte quality in pre-pubertal cats. Reproduction in Domestic Animals, 45, e405-e411. https://doi. org/10.1111/j.1439-0531.2010.01590.x

Wildt, D. E., Chan, S. Y. W., Seager, S. W. J., \& Chakraborty, P. K. (1981). Ovarian activity, circulating hormones, and sexual behavior in the cat. I. Relationships during the coitus-induced luteal phase and the estrous period without mating. Biology of Reproduction, 25, 15-28. https://doi.org/10.1095/biolreprod25.1.15

How to cite this article: Vercellini R, Gobello C, D'Francisco F, et al. Ultrasonographic evaluation of ovarian morphology and blood flow in prepubertal and pubertal cats. Reprod Dom Anim. 2018;53(Suppl. 3):74-78. https://doi.org/10.1111/rda.13355 